\title{
DESCRIÇÕES DE TÉCNICAS DA QUÍMICA NA PRODUÇÃO DE BENS DE ACORDO COM OS RELATOS DOS NATURALISTAS VIAJANTES NO BRASIL COLONIAL E IMPERIAL.
}

\author{
Soraya Vita e Fernando J. Luna* \\ LCQUI - Centro de Ciência e Tecnologia, Universidade Estadual do Norte Fluminense, Av. Alberto Lamego, 2000, 28013-602 \\ Campos dos Goytacazes - RJ, Brasil \\ Simonne Teixeira \\ LEEA - Centro de Ciências do Homem, Universidade Estadual do Norte Fluminense, Av. Alberto Lamego, 2000, 28013-602 \\ Campos dos Goytacazes - RJ, Brasil
}

Recebido em 30/10/06; aceito em 27/4/07; publicado na web em 24/7/07

\begin{abstract}
EARLY CHEMISTRY TECHNIQUES AS DESCRIBED IN THE CHRONICLES WRITTEN BY TRAVELLING NATURALISTS WHO EXPLORED COLONIAL AND IMPERIAL BRAZIL. European naturalists explored Brazil in long scientific expeditions and published accounts that make up a rich and still largely untapped historiographic source for the understanding of the history of chemistry. The production of indigo dye, the manufacture of limestone, extraction and purification of saltpeter and the production of salt are discussed. Lime was used to whitewash walls and, mixed with whale oil, as cement to glue stones in buildings of the colonial period. It was prepared by burning seashells in specifically designed ovens. Saltpeter was produced by reacting naturally occurring calcium and magnesium nitrate with potassium-rich wood ashes to yield $\mathrm{KNO}_{3}$. $\mathrm{NaCl}$ was obtained by evaporating seawater under the sun. Indigo, a native plant, was cultivated and processed to produce the renowned dye, which was exported to Europe.
\end{abstract}

keywords: history of chemistry; science in Brazil; naturalists.

\section{INTRODUÇÃO}

Sob a denominação de naturalistas viajantes abrigam-se homens com diferentes formações e visões de mundo, que cruzavam o Atlântico para estudar in loco o Novo Mundo. No decurso de suas viagens escreveram longos relatos sobre os lugares que visitavam, muitas vezes com peculiar minudência. A leitura crítica destes relatos nos permite inferir em muitos campos, como o da ciência e o da etnografia. Neste trabalho realizamos uma análise sobre a descrição das técnicas típicas das ciências químicas que podem ser encontradas nos relatos dos viajantes naturalistas que exploraram o Brasil até o século XIX. Os relatos desses cronistas são uma rica fonte historiográfica ainda pouco explorada na área de história da química, e merecem uma abordagem que julgue à luz do conhecimento atual o nível de sofisticação que alcançou a prática das ciências químicas no Brasil em relação ao que se praticava na Europa nessa época ${ }^{1}$.

Nas crônicas de viagens os naturalistas registravam a descrição geográfica das regiões que percorriam, incluindo a localização precisa e o tipo de terreno, descreviam também os tipos humanos que encontravam, as populações, os plantios e as explorações que empreendiam onde quer que estivessem. Esmeravam-se em descrever os três reinos da natureza, com um interesse especial nas possibilidades de utilização prática e rentável dos produtos nativos, incluindo o reconhecimento e a análise de minerais, metais e plantas para uso medicinal, para a saboaria e tinturaria. Quando encontravam alguma das poucas fábricas existentes à época, às vezes propunham modificações que pudessem melhorá-las; costumavam criticar as ações das populações com que mantinham contato, comparando com os usos e costumes da Europa ${ }^{2}$. As novas visões do céu, do planeta, da espécie humana, da fauna e flora que se incorporaram ao estabelecimento científico e literário europeus foram

*e-mail: fernando@uenf.br fundamentais para o nascimento da ciência moderna, surgida enquanto o chamado Velho Mundo se deslumbrava com a nova realidade sendo explorada. O cenário natural, cultural e social do Novo Mundo foi fundamental para o imaginário que serviu de base para a construção da sociedade moderna, em que a ciência e os cientistas têm papel central e, até hoje a natureza e a cultura exuberantes do hemisfério conquistado ainda ativam esse imaginário ${ }^{3}$. Desse ponto de vista, o exemplo paradigmático do viajante naturalista é Charles Darwin (1809-1882), cujas idéias mais revolucionárias, inspiradas por sua passagem pelas ilhas Galápagos, tiveram consequiências duradouras que excederam o campo da ciência extravasando para a política e religião.

Moreira Leite ${ }^{4}$ refere-se a dois documentos das autoridades coloniais portuguesas com instruções de como os naturalistas deviam realizar o seu trabalho no Brasil. A minúcia das instruções relativas a todos os aspectos envolvidos no empreendimento significa que os autores desses 'manuais de instruções' deviam ter um conhecimento prévio das circunstâncias gerais da viagem e do cotidiano das atividades a que deviam se dedicar os viajantes sempre "fazendo as reflecções convenientes sobre o modo de tirar alguma utilide. de tão vastos sertões"5. Domingos Vandelli (1735-1816), professor italiano contratado pelo Marquês de Pombal para dar cursos de química e história natural em Coimbra, especificou as atividades a que se deviam dedicar os naturalistas viajantes: "análise das terras examinando seus principais constituintes para determinar a melhor configuração planta-terreno; atenção aos bosques e minas de carvão fóssil; estudos dos metais e minerais pensando no estabelecimento de fábricas para substituir os materiais importados; conhecimento de plantas alimentícias e medicinais; análise das águas minerais para fins medicamentosos"6. Uma vez que as autoridades portuguesas consideravam inútil repetir "o q. já está compilado em vários livros bem conhecidos sobre este assumpto", pode-se concluir que os naturalistas eram profissionais de quem se esperava uma erudição significativa. Como mostra a Figura $1^{8}$, os 
naturalistas trabalhando no Brasil aproveitavam-se de trabalhadores escravos, que mereceram a atenção do pintor Jean Baptiste Debret (1768-1848).

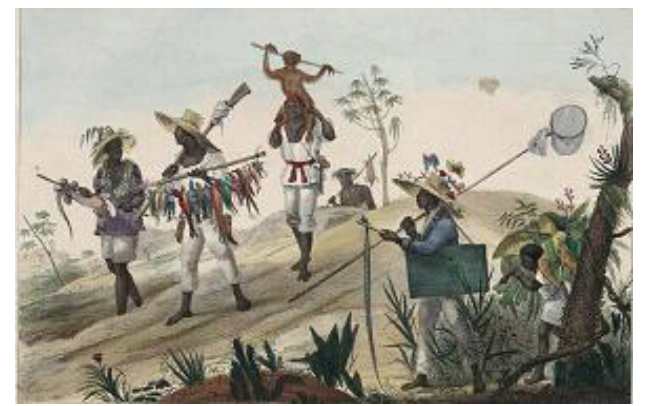

Figura 1. Negros caçadores voltando para a cidade; $O$ retorno dos negros de um naturalista (Nègres chasseurs rentrant en ville; Le retour des nègres d'un naturaliste), gravura de Jean Baptiste Debret (1768-1848) publicada por Firmin Didot frères, em 1835; Biblioteca Nacional-RJ ${ }^{8}$

O objetivo deste trabalho é descrever e comentar criticamente alguns relatos das técnicas químicas utilizadas no Brasil que podem ser encontrados nos livros deixados pelos viajantes europeus. Não existe a ambição de ser exaustivo, uma vez que pelo Rio de Janeiro passaram mais de 400 homens e mulheres que escreveram crônicas de suas viagens no século XIX, a maioria das quais somente publicados em sua língua de origem 9 .

Pero de Magalhães Gândavo (?-1579) escreve ${ }^{10}$ que já existiam engenhos de açúcar funcionando no Brasil antes de 1576, na ilha de Itamaracá em Pernambuco. O emprego pioneiro no Brasil de técnicas químicas, ou seja, filtração, extração, decantação etc. foi, portanto, para a fabricação do açúcar a partir do caldo de cana obtido por moagem ${ }^{11}$.

Tabela 1. Alguns exemplos de matérias-primas produzidas no Brasil colonial que envolviam a utilização de técnicas químicas

\begin{tabular}{|c|c|c|c|}
\hline produto & fórmula & fonte & usos \\
\hline potassa & $\mathrm{K}_{2} \mathrm{CO}_{3}$ & cinzas de vegetais & $\begin{array}{l}\text { fabricação de sabão } \\
\text { e açúcar }\end{array}$ \\
\hline soda & $\mathrm{Na}_{2} \mathrm{CO}_{3}$ & cinzas de vegetais & “ \\
\hline salitre & $\mathrm{KNO}_{3}$ & $\begin{array}{l}\mathrm{Ca}\left(\mathrm{NO}_{3}\right)_{2} \text { natural, } \\
\text { conchas }\end{array}$ & fabrico de pólvora \\
\hline sal & $\mathrm{NaCl}$ & água do mar & $\begin{array}{l}\text { alimentação, produção de } \\
\text { charque }\end{array}$ \\
\hline & $\mathrm{NH}_{4} \mathrm{Cl}$ & urina de animais & medicamento \\
\hline $\mathrm{cal}$ & $\mathrm{CaO}$ & $\begin{array}{l}\text { conchas ou } \\
\text { sambaquis }\end{array}$ & $\begin{array}{l}\text { construção e caiação de casas, } \\
\text { preparação do caldo da cana }\end{array}$ \\
\hline
\end{tabular}

Além da produção de açúcar e aguardente, até hoje de grande importância para o Brasil, as técnicas químicas descritas pelos viajantes cronistas incluem a extração do corante vermelho do pau-brasil, do corante azul da planta de anil, a fabricação de cal, a extração e purificação do salitre e a produção de sal marinho (Tabela 1). A carência de medicamentos no Brasil colonial obrigou os primeiros habitantes europeus a procurar entre os índios remédios e práticas terapêuticas baseados em plantas nativas e vários naturalistas, cronistas e historiadores registraram a riqueza da flora brasileira. Um deles, Frei Vicente do Salvador, autor de História do Brasil (de 1627), chega a afirmar, no capítulo sobre as árvores e plantas medicinais do Brasil, que "não há enfermidade contra a qual não haja ervas em esta terra"12.

\section{Produção de cal}

Se o açúcar não for levado em conta, o óxido de cálcio pode ser considerado o primeiro produto químico obtido no Brasil. A matéria-prima utilizada eram acumulações de conchas deixadas pelos índios ao longo do litoral brasileiro, chamados sambaquis. O carbonato de cálcio das conchas era transformado em óxido de cálcio ou cal virgem, que, com a adição de água transformava-se em cal extinta, o hidróxido de cálcio usado para caiar construções. A cal produzida nessas caieiras podia ser também misturada com óleo de baleia ou de peixe e utilizada para cimentar blocos de pedra na construção de edifícios. A matéria-prima para o preparo de cal não era proveniente só dos sambaquis, como observou Auguste de St. Hilaire ${ }^{13}$ :

\begin{abstract}
"de volta à Praia do Anjo, eu ia ver um forno de cal que foi construído na extremidade da vila. No Rio de Janeiro e por toda a costa até o Cabo Frio, faz-se cal com as conchas que se recolhem na borda do mar, mas, perto da Vila de Cabo Frio, na Praia do Anjo, enfim, asseguraram-me, em São Pedro dos Índios, encontra-se a pedra calcárea que se dá preferência no lugar das conchas, e, em cada um desses três lugares, existe um forno onde é queimada exclusivamente... [A pedra calcárea] é encontrada sob uma camada de terra de cerca de um palmo e meio, e é retirada em pedaços com picaretas. O forno onde é queimada [a pedra] é circular e aberto em um lado até o topo. Colocam-se no forno camadas alternadas de pedras e madeira, e se arruma no centro uma pilha de madeira, em que se põe fogo por cima. Para isto é utilizada a tingoassuiba, espécie de árvore da família das Rutáceas, que queima com extrema facilidade... ${ }^{14}$ “
\end{abstract}

Uma ilustração, feita por Jean B. Debret, desse tipo de forno de cal é mostrada na Figura 2.

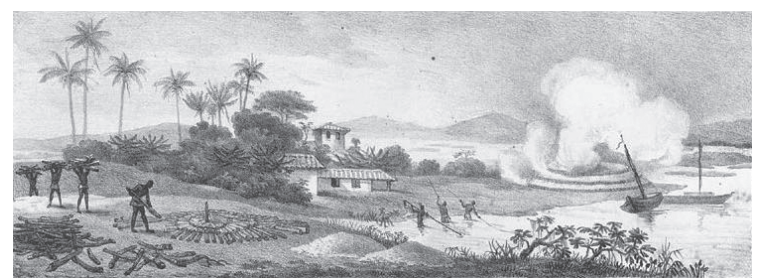

Figura 2. Fornos de cal (Fours à chaux), gravura de Jean Baptiste Debret (1768-1848) publicada por Firmin Didot Frères, em 1835; Biblioteca Nacional-RJ $J^{8}$

St. Hilaire (1799-1853) foi um naturalista estudioso da botânica que chegou ao Rio de Janeiro em junho de 1816, acompanhando o embaixador da França e ficou até 1822. Durante esse período fez cinco grandes incursões pelo país, observando e registrando as novas espécies vegetais de regiões tropicais em uma série de livros (Figura 3) ${ }^{15}$.

Em outra ocasião, em uma travessia da Baía de Guanabara, St. Hilaire afirma que "como não há rochas calcáreas nas proximidades do Rio de Janeiro, substituem-lhe a cal pela obtida das conchas. Para preparar a cal, elevam-se grandes cones colocando alternativamente, umas sobre as outras, camadas espessas de conchas e lenha, põe-se fogo. $\mathrm{O}$ trabalho de colher mariscos na água é dos mais desfavoráveis à saúde dos negros, e freqüentemente lhes causa perigosas moléstias"16.

Não era restrito aos escravos esse tipo de trabalho na Baía de Guanabara. Descrevendo o centro do Rio de Janeiro, John Luccock afirma que, já sofrendo assoreamento progressivo, no Saco da Gamboa as águas têm "três a quatro pés de fundura, fornecendo grande quan- 


\section{VOYAGE}

Dams

\section{LE DISTRICT DES DIAMANS}

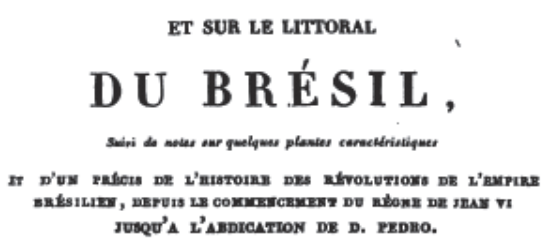

PAR AUGUSTE DE SAINT-HILAIRE,

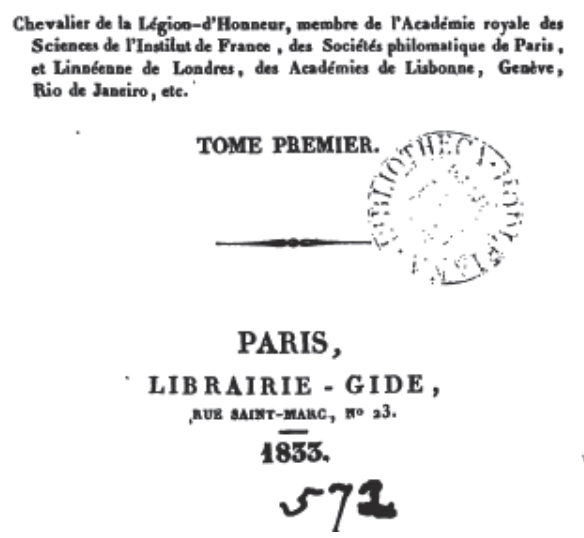

Figura 3. Folha de rosto do livro de Saint-Hilaire publicado em Paris em 1833

tidade de conchas, que as pessoas desocupadas recolhem a fim de transformar em cal"17. O comerciante inglês John Luccock morou aqui por 10 anos (1808-1818), vindo de Portugal. Ele possuía uma capacidade acurada de observação que lhe permitiu redigir, anos depois, um livro ${ }^{18}$ sobre o país que se constitui hoje em preciso documento sobre diversos aspectos da sociedade de então.

\section{Produção de salitre}

Por ser, junto com o enxofre e o carvão, a matéria-prima da pólvora, o salitre e sua produção local tornaram-se muito cedo objetivos primordiais para as autoridades portuguesas nas colônias. No Brasil o nitrato de cálcio, precursor do salitre, era encontrado em cavernas nas regiões calcáreas, formado por bactérias nitrificantes sobre matéria nitrogenada de origem animal (dejetos de morcegos e mocós) ${ }^{19}$. Havia sérios problemas logísticos no empreendimento, como explica o historiador Robert Southey em sua obra História do Brasil, de 1694. Diz ele que o governador tinha ido ao

\footnotetext{
"sertão da Bahia explorar umas minas de salitre, que se esperava tornassem desnecessário importar da Ásia este artigo. Confiando inteiramente no bom resultado, levou ele [o governador] consigo logo uma companhia completa de gente para extrair o mineral, e desembarcando na vila de Cachoeira no Recôncavo, deu-se princípio à jornada por terra. Muito pelo interior adentro jaziam as minas, para tornar acessiveis as quais cumprira abrir caminhos. Ensaiaram-se ela em quatro lugares diversos, construíram-se obras, em sacos de couro se mandou para a Bahia o nitro; não tardaram porém a reconhecer-se as despesas e inconvenientes de um transporte de trezentas milhas por terra, abandonando-se o pouco judicioso projeto ${ }^{20 .}$."
}

O engenheiro de minas Wilhelm Ludwig von Eschwege (17771855) estudou na Universidade de Gottingen e começou a trabalhar para o governo português em 1803, chegando ao Brasil em 1810, onde ficou por onze anos. Sua principal obra, Pluto Brasiliensis, (de 1833) ${ }^{21}$, é um tratado histórico, estatístico e técnico de 600 paginas sobre a indústria de mineração no Brasil e sobre os minerais de interesse industrial. A técnica de refino do salitre usada em 1816 é descrita por Eschwege, que então já havia sido nomeado por D. João diretor do Real Gabinete Mineralógico:

\footnotetext{
"A terra, em pedaços muito duros, é, em primeiro lugar, quebrada grosseiramente por meio de macetes, e, então, levada às caixas de lavagem, cavadas em grossos troncos de árvore. As águas de lavagem são fervidas em 6 caldeiras, cada uma das quais mede 6 palmos de diâmetro e profundidade. A mistura alcalina é feita à parte e depois juntada às águas de lavagem. É preparada com as cinzas das madeiras mais rijas, sobretudo a aroeira ${ }^{22}$."
}

O objetivo da adição das cinzas ("mistura alcalina") é transformar os nitratos de cálcio e magnésio em nitrato de potássio, por reação com o carbonato de potássio das cinzas, quando se precipitam os carbonatos alcalinoterrosos e o nitrato de potássio, ou salitre, permanece em solução. Continua Eschwege:

\begin{abstract}
"Em uma caldeira à parte, as águas mães são de novo fervidas e então filtradas num vaso de madeira, onde o salitre se cristaliza. Como isto se dá antes da cristalização do cloreto de sódio, aproveita-se esse tempo para tirar o resto das águas mães e preparar um sal de cozinha impuro, contendo ainda salitre. Este sal serve para a alimentação do gado, que, no Brasil, geralmente, não pode desenvolver-se sem o auxílio dessa substância ${ }^{23}$."
\end{abstract}

Em recente artigo $^{24}$ a descrição detalhada do processo nos ensina que camadas do solo rico em salitre e camadas de cinza eram colocadas em tonéis alternadamente, às vezes com camadas de palha para facilitar a passagem da água. Em uma cavidade feita na parte de cima desse arranjo era adicionado carbonato de potássio e, em seguida, água. Depois de algum tempo a água saturada com o salitre era conduzida através de torneiras ou de orifícios até então fechados para caldeiras, onde, por evaporação, se podia recuperar o salitre. Durante o processo de evaporação, era removido com uma escumadeira todo o cloreto de sódio que ia se formando, até restar apenas o líquido. Depois da total evaporação, obtinha-se finalmente o salitre "bruto ou impuro", que ainda iria ser refinado em outra etapa. Esse processo de adição de água sobre a terra rica em salitre é chamado lixiviação, cujo objetivo é separar por dissolução os componentes solúveis incluindo o salitre.

Charles Ribeyrolles (1812-1860), jornalista e político francês, viajou para o Brasil em 1858, depois de ser exilado pelo regime de Napoleão III. Estudou e observou o país registrando as suas impressões no livro Brazil pittoresco $^{25}$, cuja folha de rosto é mostrada na Figura 4.

Nas notas finais de seu relato ${ }^{26}$ encontra-se uma lista de madeiras encontradas na Província do Rio de Janeiro e uma menção ao uso que se dava às cinzas de uma delas, onde se lê: "GOURAREME: Madeira cujas cinzas servem para refinar o açúcar, em razão da grande quantidade de potassa que encerra. Abarema, algodão, pitomba preta e amarela têm as mesmas propriedades ${ }^{27}$."

\section{Produção de cloreto de sódio}

De acordo com Katinsky ${ }^{28}$, Gabriel Soares de Souza já registrava a facilidade com que se poderia produzir sal abundantemente 
BRAZIL PITTORESCO

\author{
HISTORIA - DESCRIPCÕIES - VLAGKNS - INSTTTUI,0̃ES \\ BoLovisaç̃o.
}

\author{
nos

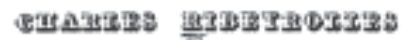 \\ ACOMPAMHADO DE UM ALBUW DE VISTAS,
}

PANORAMAS, PAISAGERS, EOSTUNIES, BTG., ETE.

raegos arosid

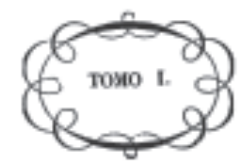

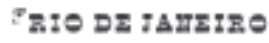

TYPOGRAPHIA NACIONAL.

1859.

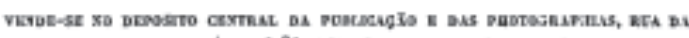

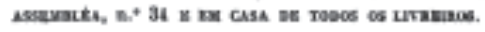

Figura 4. Folha de rosto de uma edição bilíngüe do livro de Charles Ribeyrolles de 1859

nas costas brasileiras, seguindo o mesmo processo usado em Portugal, em sua obra Tratado Descriptivo do Brazil, de 1587. Nas margens do rio Una, na região norte do Rio de Janeiro próxima a Cabo Frio, St. Hilaire ${ }^{29}$ registrou ter visto "sal branco como a neve. Este sal magnífico se forma por evaporação natural, em buracos onde o mar deixa a água depois das marés altas, e os habitantes do país têm o cuidado de recolhê-lo"30.

$\mathrm{Na}$ Metrópole, a extração do sal marinho remonta aos tempos da dominação romana e os portugueses encontraram condições favoráveis para o empreendimento em toda a costa brasileira desde o Maranhão até a altura de Cabo Frio, ou seja, altas temperaturas ambientes, concentração salina alta na água e constantes ventos. Ao contrário da prática atual, em que o maior uso do cloreto de sódio se destina à produção de cloro gasoso, na época servia principalmente para alimentação humana e dos bois e cavalos, além da preparação do charque pelo salgamento da carne bovina e seca sob o sol. Não se pode esquecer da importância do sal como matériaprima na Europa, especialmente para a expressiva produção de bacalhau, arenque e outros peixes que eram importantes nas economias de Portugal, Holanda e dos países escandinavos ${ }^{31}$.

Como em Portugal, o sal marinho era produzido no Brasil pelo armazenamento de uma parte da água do mar em sucessivos compartimentos de diferentes dimensões. "Barragem" era chamado o primeiro compartimento, com área entre 1000 e $3000 \mathrm{~m}^{2}$, onde entrava diretamente a água do mar. Com a ação do vento e do sol, na barragem a água começava a evaporar e daí era distribuída para os cercos, que eram espaços menores $\left(600-1000 \mathrm{~m}^{2}\right)$ com uma profundidade entre
$80 \mathrm{~cm}$ e $1 \mathrm{~m}$. Depois dos cercos, a salmoura ainda passava pelo compartimento chamado "chocador", que media entre 400 e $800 \mathrm{~m}^{2}$. No último compartimento, o cristalizador, de 50 a $400 \mathrm{~m}^{2}$, ocorria a precipitação do cloreto de sódio, que era recolhido com o uso de instrumentos rudimentares, castigando duramente o trabalhador ${ }^{32}$.

Von Martius descreveu o processo de obtenção do sal de cozinha, por volta de 1820, a partir da dissolução das terras salinas, fazendo passar o soluto através de gravetos e areia suportados por um couro de boi furado, formando um sistema filtrante rudimentar. Em seguida evaporava-se o soluto com certa facilidade por causa das altas temperaturas e baixa umidade do ar típicas da região dos lagos no norte do estado do Rio de Janeiro, obtendo-se o sal precipitado ${ }^{33}$.

Carl F. P. von Martius era professor de botânica na Universidade de Berlim e chegou ao Brasil com a missão austríaca patrocinada pelo Imperador Francisco I, pai de Leopoldina da Áustria quando ela veio para o Rio de Janeiro para casar-se com o príncipe Pedro de Alcântara. A obra em três volumes intitulada Viagem ao Brasil foi o resultado dessa expedição $0^{34}$.

\section{Produção do corante azul de anil}

Mesmo não sendo de preparo trivial, o índigo ou anil foi o primeiro corante vegetal a ser explorado pelo homem, e tanto Dioscórides (século I), autor greco-romano fundador da farmacognosia, quanto Plínio o Velho $(23-79)^{35}$ já se referiam na Antiguidade ao corante oriundo da Índia que era denominado indikon, indicum, inde, endice, anil ou indigo. Até 1856, ano em que o químico inglês William Henry Perkin (1838-1907) sintetizou a malveína, todos os corantes e pigmentos eram extraídos de seres vivos ou de minerais. Ainda no século XVIII os mais importantes tratados publicados sobre corantes eram dos autores franceses Jean Hellot (1685-1766), Claude Berthollet (1748-1822) e Pierre Joseph Macquer (1718-1784), que, sob os auspícios da Academia de Ciências de Paris, dedicavam-se ao desenvolvimento da indústria de corantes $^{36}$. Em obra de 1820, Pizarro e Araújo descreve a planta do anil, mostrada na Figura 5, como sendo "um arbusto, de cujas folhas, postas de molho por certos dias, se tira a massa azul, que tem o mesmo nome, e serve na tinturaria, depois de beneficiada por uma fabrica particular" ${ }^{37}$.

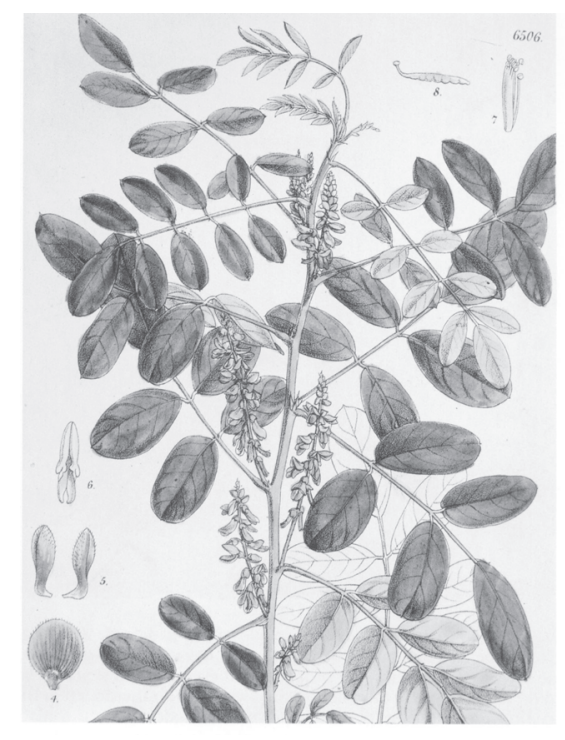

Figura 5. Planta do anil. Botanical Magazine vol. XXXVI (serie 3). Real Jardin Botanico, Madri ${ }^{36}$ 
O anil era de ocorrência nativa no Brasil, como indica Ambrósio Fernandes Brandônio no diálogo quarto de seu livro de 1618 intitulado Diálogo das Grandezas do Brasil ${ }^{38}$ :

"[...] com haver tempo que se descobriu, e pode ser que fosse eu o primeiro descobridor dela, tão pouca curiosidade mora por estas partes; das quais não se pode desinçar a herva de que se faz o anil, a qual na Índia se planta e grangeia com muito cuidado e diligência, e aqui nasce sem nenhuma indústria, e a pouco trabalho se poderá dela fazer copia grande de anil, e eu o experimentei já, e fiz um pouco tal e tão bom que não podia ter inveja ao que se lavra nas Índias."

Pedaços da planta do anil, colhida antes do início da floração, eram deixados fermentando em um tanque durante um período de tempo entre 10 e $40 \mathrm{~h}$. Neste tanque, uma grade de madeira esmaga as folhas para provocar a saída do anil. A água, com o anil já dissolvido, passa ao segundo tanque, onde um agitador movido a tração animal provoca a precipitação. Para um tanque comunicante era transferido somente o líquido resultante da fermentação, onde era batido durante várias horas até ocorrer a precipitação do sólido azul. O anil era espalhado sobre telas onde era espremido até se formarem torrões e em seguida secados ao sol. Era utilizado também um concentrado de anil que agia como semente para facilitar a formação do precipitado ${ }^{39}$. As pequenas "pedras" assim obtidas ou por variantes deste método podiam ser utilizadas para tingir fios e tecidos de lã, algodão ou seda. $\mathrm{O}$ composto encontrado na planta é a indicana, um glicosídeo precursor, que durante a fermentação é convertido em glicose e um leuco-composto, que oxida em contato com o ar e adquire a cor azul típica ${ }^{40}$. Ferraz afirma que o frei José Marianno da Conceição Velloso (1741-1811), em sua obra $O$ Fazendeiro do Brasil $^{41}$, já ensaiava explicações elaboradas para o processo de fabricação do anil:

"Segundo diversos autores, a fermentação-etapa absolutamente necessária - começaria a promover a reunião das partículas colorantes. Nessa etapa, as partículas azuis e amarelas estariam ainda juntas, daí a coloração verde do líquido. A etapa seguinte-quando o líquido da fermentação separado no segundo tanque era batido-faria com que as particulas colorantes azuis se separassem das amarelas, juntando-se e depositando-se no fundo do segundo tanque. Depois disso era recolher a pasta, secá-la, dar-lhe forma e promover a secagem completa das pedras" 40.

O livro de Frei Veloso traz a tradução para o português de uma obra escrita por Quatremer Dijonval intitulada Analyse e exame chymico do Indigo que se acha no Commercio para as tinturari$a s^{42}$, em que o autor afirma que a destilação da planta fornecia: "água cheirosa, espírito álcali volátil e óleo verdoengo empireumático (uma parte leve, outra pesada), além de carvão" 40. Um óleo empireumático é aquele produzido por destilação destrutiva de substâncias orgânicas e 'espírito álcali volátil' é a amônia.

St.-Hilaire refere-se ao trabalho de Dijonval publicado em 1780 que incluía "os detalhes sobre a cultura das indigoferas e a extração de sua fécula" 43 em um artigo intitulado "Histoire de l'indigo, depuis l'origine des temps historiques jusqu'à l'année 1833" em que descreve toda a bibliografia disponível à época sobre a origem, plantação e métodos de preparo do anil. Duas passagens são interessantes. Na primeira, St.-Hilaire cita um trecho da tradução feita em 1586 para o francês do relato do viajante Marco Pólo (1254-1324) ${ }^{43}$ :

"onde cresce uma certa erva da qual os tintureiros preparam uma cor que chamam "endice", que é maravilhosamente prazerosa e agradável, e se prepara tal erva desta forma. Primeiramente eles a ensopam com água em vasilhas, e depois tendo-as secado ao sol, dividem-na em pedaços bem pequenos na forma de pequenas pedras, que é como será transportada ao país de destino" ${ }^{44}$.

No outro trecho interessante desse $\operatorname{artigo}^{43}$, St.-Hilaire referese ao Brasil, afirmando que encontrou aqui uma planta que fornece uma cor azul ainda mais bela que o anil:

"Basta citar um Solanum brasileiro do qual se pode tirar uma cor azul escura mais bela até mesmo que o indigo. É um arbusto que se encontra perto da vila de Piumhy, na província de Minas Gerais, e que, se não me engano, existe em todos os bosques virgens um pouco úmidos das províncias do Rio de Janeiro, Espírito Santo e Minas Gerais." ${ }^{45}$

Foi o Marquês do Lavradio, vice-rei do Brasil, quem incentivou a produção de anil no Brasil instituindo um preço mínimo e determinando que a Fazenda Real adquirisse a oferta existente. O próprio marquês era proprietário de uma fábrica de índigo localizada no Rio de Janeiro. No fim do século XVIII Cabo Frio tornouse importante pólo produtor de anil, com 206 fábricas que exportavam sua produção para a Europa ${ }^{46}$. Quando descreve a cidade de Vassouras, no Rio de Janeiro, Charles Ribeyrolles menciona a cultura do anil em seu Brazil pittoresco ${ }^{47}$ :

"A primeira grande cultura do município [de Vassouras] foi o anil. Planta da América e das Índias, ali dava-se bem, produzia bastante, e o pouco peso do seu sedimento azul conseguia bom preço, apesar da distância ao mercado longínquo. [...] O anil é planta autóctone, pois encontra-se nas capoeiras; e se a espécie não era a melhor, cumpria procurar alhures: uma cultivação inteligente melhora todos os planos." 48

Outro viajante que aqui esteve à época da chegada da Família Real expulsa da Europa pelos invasores franceses foi John Luccock, que escreveu:

"Fronteira à casa em que residíamos, ficava uma ilha contendo apenas uns poucos acres de terra plantada com anil. Compramo-la, na intenção de realizar experiências sobre o crescimento e preparação dessa preciosa tintura, na suposição de que o descrédito em que na Inglaterra caíra o anil fosse devido apenas à má direção. Os fabricantes, no extraírem a fécula, ao invés de usarem água de cal pura, estavam habituados a jogar dentro da tina tamanha quantidade de cal em pedra que o líquido não conseguia absorver essa substância, precipitando-se no fundo o excesso juntamente com o anil, ali se solidificando e transformando-se numa espécie de calcáreo azulado. Era nesse estado miserável que o exportavam e, como pesava muito mais que o anil não adulterado, resultava num lucro imediato maior para o fabricante, mas arruinou o crédito do artigo." ${ }^{49}$

Então aqui, de fato, o que se estava exportando para a Europa eram pedras de cal tingidas por fora de azul de anil, como se fosse o extrato puro da planta. Cerca de dois meses depois, às vésperas da colheita, Luccock foi notificado que estrangeiros não poderiam possuir terras costeiras, e que, portanto, teria de abandonar imediatamente a ilha, podendo, se assim o desejasse, instalar-se do outro lado das montanhas, no interior. Luccock ainda relata que o emissário do príncipe, um alto funcionário "foi ao ponto de lembrar abertamente que uma propina que lhe déssemos poderia ainda 
garantir-nos a satisfação dos nossos desejos" ${ }^{50}$. Não se submetendo ao achaque, tiveram os ingleses de desistir do empreendimento.

\section{CONCLUSÕES}

A leitura crítica dos relatos dos naturalistas que exploraram o Brasil tem sido importante como fonte historiográfica em campos tão diversos quanto a etnologia e a economia, mas, como mostramos aqui, também pode trazer à luz novos conhecimentos sobre a história da química no Brasil.

Segundo os exemplos apresentados, não faltou empenho dos naturalistas de diversas origens e dos funcionários do governo português para levar a cabo a prospecção e execução de trabalhos práticos visando a exploração comercial dos recursos naturais encontrados no Brasil. Os métodos e processos químicos utilizados eram eficientes para os fins pretendidos, sendo baseados nos conhecimentos da ciência praticada em Portugal, sob influência marcante de autores franceses. Estavam, portanto, em sintonia com o centro mais avançado no começo do século XIX.

\section{AGRADECIMENTOS}

Ao anônimo assessor desta revista que fez valiosíssimas sugestões e à Profa. P. M. Martins pela revisão das traduções do francês.

\section{REFERÊNCIAS E NOTAS}

1. Filgueiras, C. A. L.; Quim. Nova 2001, 24, 709; Pinto, A. C.; Quim. Nova 1995, 18,608 .

2. Ferraz, M. H. M.; As ciências em Portugal e no Brasil, 1772-1822: o texto conflituoso da química, EDUC: São Paulo, 1997, p. 169.

3. D’Ambrosio, U. Em Escrevendo a história da ciência: tendências, propostas e discussões historiográficas; EDUC: São Paulo, 2004, p. 173

4. Leite, M. L. M.; Hist. Ciênc. Saúde-Manguinhos 1995, 1, 7.

5. Apud Leite, M. L. M.; op. cit.

6. Apud Ferraz, M. H. M.; op. cit., p. 153.

7. Apud Leite, M. L. M.; op. cit.

8. http://catalogos.bn.br/digital/, acessada em Outubro 2006.

9. Berger, P.; Bibliografia do Rio de Janeiro de viajantes e autores estrangeiros, 1531-1900, Livraria São José: Rio de Janeiro, 1964.

10. Gandavo, P. de M.; Tratado da terra do Brasil; História da Província Santa Cruz, Itatiaia/Edusp: B. Horizonte/São Paulo, 1980, p. 25.

11. Carrara Jr., E.; Meirelles, H.; A indústria química e o desenvolvimento do Brasil, Metalivros: São Paulo, 1996, tomo I, p. 98.

12. Salvador, V. do; Historia do Brazil, Bibliotheca Nacional: Rio de Janeiro, 1889 , p. 16.

13. Saint-Hilaire, A. de; Voyage dans l'intérieur du Brésil Seconde Partie. Voyage dans le district des diamans et sur le littoral du Brésil, Gide: Paris, 1833, tome II, p. 59.

14. "De retour à la Praia do Anjo, j'allai voir un four à chaux qui a été construit à l'éxtremité du village. A Rio de Janeiro et sur toute la côte jusqu'au Cap Frio, on fait de la chaux avec des cames que l'on ramasse sur le bord de la mer; mais, près de la ville du Cabo Frio, à la Praia do Anjo, enfin, m'a-t-on assuré, à $\mathrm{S}$. Pedro dos Indios, on trouve de la pierre calcaire qu'on préfère aux coquillages, et, dans chacun de ces trois endroits, il existe un four où on la brûle exclusivement. L'endroit d'où se tire la pierre à Praia do Anjo est plat et marécageux: on la trouve sous une couche de terre d'environ une palme et demie, et on la détache par morceaux avec des pics. Le four où on la brûle est circulaire et ouvert d'un coté dans toute sa hauteur. On y met des couches alternatives de pierres et de bois, et l'on arrange au centre une pile de bois à laquelle on met le feu par en haut. On se sert à cet effet, du tingoassuiba (Zanthoxylum tingoassuiba...), espèce d'arbre de la famille des Rutacées, qui brûle avec une facilité extreme".

15. Belluzzo, A. M. de M.; O Brasil dos viajantes, Metalivros: São Paulo, 1994, vol. 2 , p. 158.

16. Saint-Hilaire, A. de; Viagem pelas Provincías do Rio de Janeiro e Minas Gerais, Itatiaia/Edusp: B. Horizonte/S. Paulo, 1975, p. 18.

17. Luccock, J.; Notas sobre o Rio de Janeiro e partes meridionais do Brasil, Ed. Itatiaia/Edusp: B. Horizonte/S. Paulo, 1975.

18. Ibidem

19. Carrara Jr., E.; op. cit., p. 133-138.
20. Southey, R.; História do Brasil, Itatiaia/Edusp: B. Horizonte/S. Paulo, 1981, vol. 3, p. 19.

21. von Eschwege, W. L; Pluto Brasiliensis, Itatiaia/Edusp: B. Horizonte/S. Paulo, 1979.

22. Ibidem

23. Ibidem

24. Ferraz, M. H. M.; Quim. Nova 2000, 23, 845.

25. Ribeyrolles, C.; Brazil pittoresco: historia-descripções-viagens-instituiçõescolonisação, Typographia Nacional: Rio de Janeiro, 1859.

26. Ribeyrolles, C.; op. cit., p. 189.

27. "GOURAREME: Bois dont la cendre sert a nettoyer le sucre, par la grande quantité de potasse qu'elle contient. ABARENO, ALGUDÃO, PITOMA NOIRE ET JAUNE Tous ces bois possèdent les mêmes propriétés que le Gourareme."

28. Katinsky, J. R. Em História da técnica e da tecnologia no Brasil; Vargas, M., ed.; Editora UNESP: São Paulo, 1995, p. 99-101.

29. Saint-Hilaire, A. de; Voyage dans l'intérieur du Brésil Seconde Partie. Voyage dans le district des diamans et sur le littoral du Brésil, Gide: Paris, 1833, tome II, p. 211.

30. "du sel blanc comme la neige. Ce sel magnifique se forme par une évaporation naturelle, dans des creux où la mer laisse de l'eau à la suite des marées hautes, et les habitans du pays ont grand soin de le recueillir".

31. Feinberg, H. M.; Trans. Amer. Phil. Soc. 1989, 79, 1.

32. Katinsky, J. R.; op. cit.

33. Carrara Jr., E.; op. cit., p. 133.

34. Prantner, J.; Imperatriz Leopoldina no Brasil, Vozes: Petrópolis, 1997, p. 123.

35. No capítulo 27 do livro 35 de Naturalis Historia, Plínio escreve que "em seguida a este, [o purpurissum,] o mais estimado é o anil, uma produção da Índia, sendo um lodo que adere à espuma sobre as arundinárias ali. Quando em pó, é negro em aparência, mas quando diluído em água produz uma maravilhosa combinação de púrpura e cerúleo". No original, obtido em http:/ /penelope.uchicago.edu/Thayer/L/Roman/Texts/Pliny_the_Elder/35*.html, acessada em Outubro 2006, lê-se: "Ab hoc maxime auctoritas Indico. ex India venit harundinum spumae adhaerescente limo. cum cernatur, nigrum, at in diluendo mixturam purpurae caeruleique mirabilem reddit."

36. Blanco, A. G. Em La agricultura viajera, cultivos y manufacturas de plantas industriales y alimentarias en España y en la América Virreinal; Pérez, J. F.; Tascón, I. G., eds.; Consejo Superior de Investigaciones Científicas: Madrid, 1990, p. 195.

37. Pizarro e Araújo, J. de S. A.; Memorias historicas do Rio de Janeiro e das provincias annexas a jurisdiccão do vice-rei do estado do Brasil, Impressão Régia: Rio de Janeiro, 1820.

38. Brandão, A. F.; Diálogos das grandezas do Brasil, Progresso: Salvador, 1956.

39. Blanco, A. G.; op. cit.

40. Ferraz, M. H. M.; Anais do VII Seminário Nacional de História da Ciência e da Tecnologia, São Paulo, Brasil, 2000.

41. A obra de 10 volumes, impressa em Lisboa e enviada ao Brasil para ser vendida a preços módicos, ou mesmo distribuída aos colonos se intitula: $O$ Fazendeiro do Brasil, cultivador, melhorado na economia rural dos gêneros já cultivados e de outros, que se podem introduzir e nas fábricas, que lhe são próprias, segundo o melhor, que se tem escrito a este assumpto, 1798-1806.

42. O título do trabalho original que ganhou um prêmio da Académie Royale de Paris é "Analyse et examen chymique de l'indigo, tel qu'il est dans le commerce pour l'usage de la teinture"; Mém. de mathém. et de phys. de l'A. R. de Paris; T. 9, pp. 3-164.

43. Saint-Hilaire, A. de; An. des Sc. Nat.-botanique 2(7), Clochard: Paris, 1837, p. 110.

44. "oultre croît une certaine herbe de laquelle les teincturiers font une couleur qu'ils appellent endice qui est merveilleusement plaisante et agréable, et se prepare telle herbe em ceste forme. Premièrment ils la font tremper en certains vaisseaux pleins d'eau, puis, l'ayant fait dessécher au soleil, la divisent bien menu et rompent en petites pierres en telle forme qu'elle est à present transportée au pays deçà".

45. "Je me contenterai de citer un Solanum brésilien dont on peut tirer une couleur bleue foncée plus belle que l'indigo lui-même. [...] C'est un arbrisseau qui se trouve près du village de Piumhy, dans la province de Mines, et qui, si je ne me trompe, existe dans tous les bois vierges un peu humides des provinces de Rio de Janeiro, Espirito Santo, Minas Geraes, et probablement ailleurs encore".

46. Carrara Jr., E.; op. cit., p. 133-138.

47. Ribeyrolles, C.; op. cit., p. 94

48. "La première grande culture du Municipe fut l'indigo; cette plante de l'Amérique et des Indes y venait bie, y faisait merveille, et le poids de sa fécule bleue laissait de beaux prix, malgré les distances, sur les marchés lointains. [...] L'anil est plante autochtone, puisq'on le trouve dans les Capoeiras, et si l'éspece n'était pas la meilleure, il en fallait prendre ailleurs: une habile culture reléve tou les plans".

49. Luccock, J.; op. cit., p. 184

50. Ibidem 